Supplement of Arch. Anim. Breed., 62, 537-545, 2019

https://doi.org/10.5194/aab-62-537-2019-supplement

(C) Author(s) 2019. This work is distributed under

the Creative Commons Attribution 4.0 License.

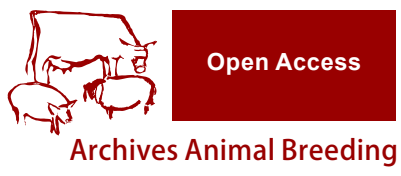

(c) (1)

Supplement of

\title{
Valuing breeders' preferences in the conservation of the Koundoum sheep in Niger by multi-attribute analysis
}

Issa Hamadou et al.

Correspondence to: Nicolas Antoine-Moussiaux (nantoine@uliege.be)

The copyright of individual parts of the supplement might differ from the CC BY 4.0 License. 


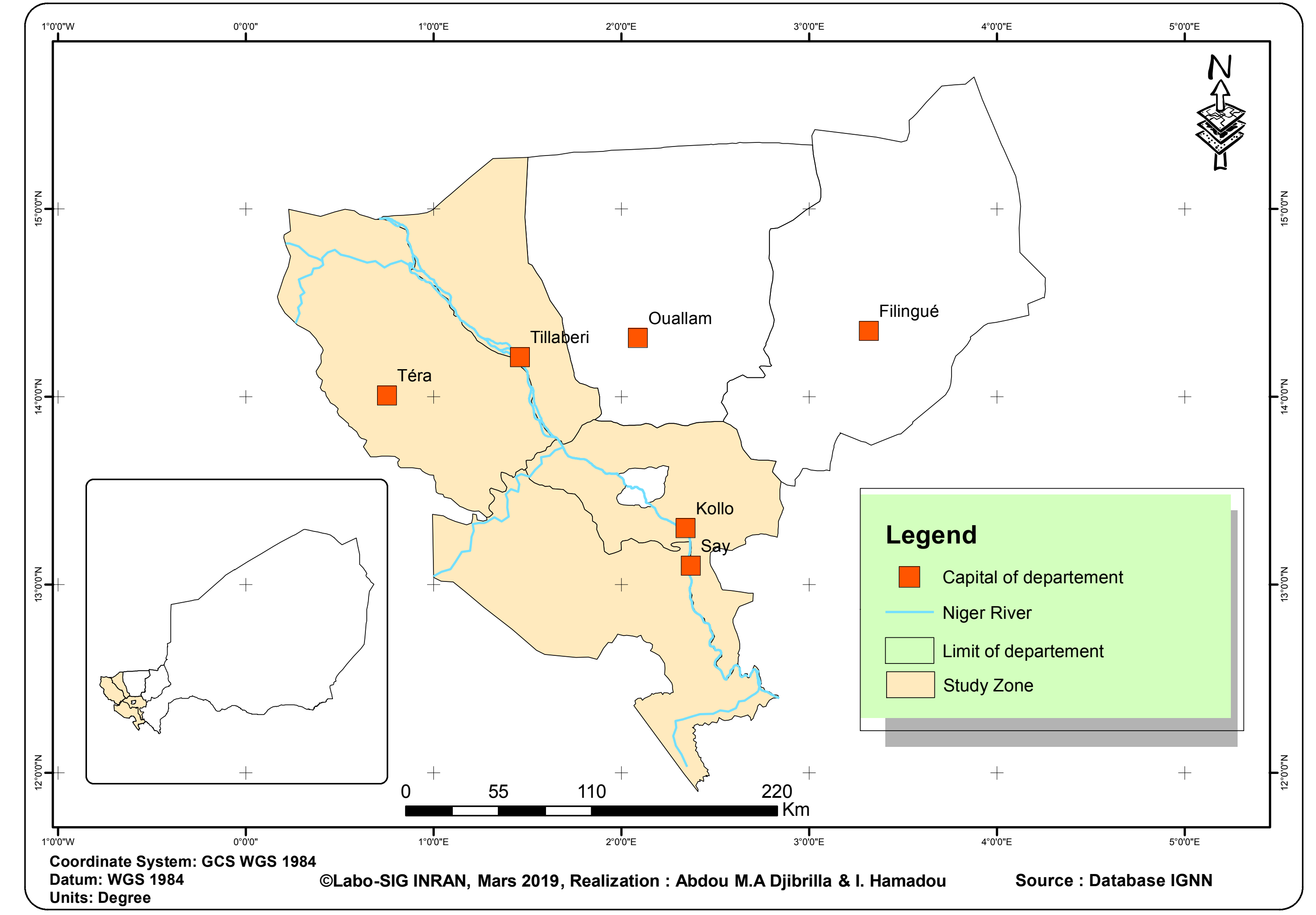

